\title{
New materials strategies for creating hybrid electronic circuitry (Presentation Video)
}

\section{Tobin Marks}

Tobin J. Marks, "New materials strategies for creating hybrid electronic circuitry (Presentation Video)," Proc. SPIE 8831, Organic Field-Effect Transistors XII; and Organic Semiconductors in Sensors and Bioelectronics VI, 88312A (25 August 2013); doi: 10.1117/12.2050975

SPIE Event: SPIE Organic Photonics + Electronics, 2013, San Diego, California, United States 


\title{
New Materials Strategies for Creating Hybrid Electronic Circuitry (Presentation Video)
}

\author{
Tobin J. Marks, Northwestern Univ. (United States)
}

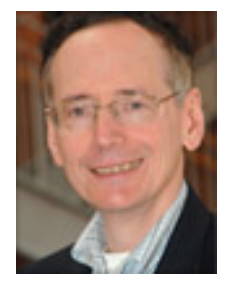

\begin{abstract}
This lecture focuses on the challenging design and realization of new materials for creating unconventional electronic circuitry. Fabrication methodologies to achieve these goals include high-throughput, large-area printing techniques. Materials design topics to be discussed include: 1 . Rationally designed high-mobility $\mathrm{p}$ - and n-type organic semiconductors for printed organic CMOS, 2. Polycrystalline and amorphous oxide semiconductors for transparent and mechanically flexible electronics, 3) Self-assembled and printable high-k nanodielectrics enabling ultra-large capacitance, low leakage, high breakdown fields, minimal trapped interfacial charge, and device radiation hardness. 4) Combining these materials sets to fabricate a variety of high-performance thin-film transistor-based devices.
\end{abstract}

View presentation video on SPIE's Digital Library: http://dx.doi.org/10.1117/12.2050975 